\title{
Joining Technologies for Metal Additive Manufacturing in the Energy Industry
}

\author{
MILO GILL, ${ }^{1}$ ETHAN TERRY, ${ }^{1}$ YUSUF ABDI, ${ }^{1}$ STANTON HAWKES, ${ }^{2}$ \\ JACOB RINDLER, ${ }^{1}$ DAVID SCHICK, ${ }^{3}$ ANTONIO RAMIREZ, ${ }^{2}$ \\ and EDWARD D. HERDERICK (i) ${ }^{1,4}$
}

1.-Center for Design and Manufacturing Excellence, The Ohio State University, Columbus, $\mathrm{OH}$ 43212, USA. 2.-Department of Materials Science and Engineering, The Ohio State University, Columbus, OH 43212, USA. 3.-Proto Precision Additive, Hilliard, OH 43026, USA. 4._e-mail: herderick.2@osu.edu

Additive manufacturing (AM) has captured the imagination of the manufacturing community and has revolutionary potential across a number of energy applications. One particular challenge for these applications is the large size of metal AM components that are compelling to be printed. This necessitates welding and joining processes to integrate metal AM parts into larger assemblies, as well as the ability to repair and re-work metal AM parts that may have defects. This work characterizes the microstructural and mechanical properties of metal parts produced through laser-based powder bed fusion (L-PBF) and electron beam powder bed fusion (EB-PBF) and then subsequently welded. The results show possibilities for gas tungsten arc welding (GTAW) and friction stir welding (FSW) as feasible rework and repair solutions for AM-printed AlSi10Mg, Ni 718, and Ti64. More research attention to this area will improve the viability of L-PBF and electron beam melting AM technology for energy applications.

\section{INTRODUCTION}

Additive manufacturing (AM) has the potential to revolutionize the way that metal parts are made for the energy industry. Reduced lead times, optimized part geometry, and cost and weight reductions with increased performance all drive interest in the technology. In order to fully industrialize the use of metal AM components, approaches for joining and repair will be required, particularly for energy applications where components can fill the entire build chamber, and assemblies including AM components can easily be many cubic meters in size.

Metal powder bed fusion (PBF) is a subset of AM whereby a laser or electron beam is used to consolidate metal in powder form to construct threedimensional elements. PBF techniques share the

(Received August 10, 2020; accepted October 6, 2020; published online October 29, 2020) basic principles of all AM techniques (e.g., layer-bylayer fabrication directly from 3D model data), as well as common advantages such as cost-effective customization and reduced assembly. PBF processes have a significant advantage over many other AM processes in that they have the ability to print very fine and detailed components in industrial metal alloys. $^{1}$

Large PBF-built parts are expensive and can easily cost $\$ 20,000$ USD and more depending on post-processing complexity and alloy system. Saving the cost and time of a replacement print for a partially failed build or extending the life of parts in circulation would improve the value in PBF AM and enable more energy applications. Furthermore, the design of many components requires complexshaped modules that join metal components to the AM-printed component. A reliable joining technology provides enhanced design flexibility for AM modules that would otherwise be impossible to produce due to bed size limitations of the equipment. 
This work investigated Ni 718, Ti-6Al-4V (Ti64), and AlSi10Mg printed by PBF and joined using several welding processes. The $\mathrm{Ni} 718$ and AlSi10Mg were printed using laser-based powder bed fusion (L-PBF) and the Ti64 was printed using electron beam powder bed fusion (EB-PBF) as described in the experimental procedure section. Gas tungsten arc welding (GTAW) was performed on plates printed from all three materials and friction stir welding (FSW) was performed on the AlSi10Mg. The goal of this investigation was to determine if components produced through PBF could be welded without negatively affecting their structural and mechanical properties.

The current openly published literature is limited and illustrated by the following example: the NASA MSFC standard for additively manufactured spaceflight hardware by L-PBF in metals covers aspects of design, production, and control extensible with the notable exception of any detailed information on welding. Section 6.2.13.4 on the topic of welding is quite brief and suggests "Unique preparation and sequencing may be involved in welding of L-PBF parts" 2

The motivation behind this work is represented by several use cases. One case is printing support failure and generation of foreign object debris (FOD) from broken supports during metal PBF printing as shown in Fig. 1. This occurs when support material pulls away from the part creating a defect directly at the part-support interface, or when FOD is dragged across the build bed creating a macroscopic defect. Another case is a short feed of powder that can cause a section of the part to not fully form. Another case is damage during support removal, removal from the build plate, or defects created during machining, e.g., a mis-drilled hole. In each of these scenarios, it would be advantageous to have a rework repair solution for as-printed condition metal parts. As such, this work has focused on the as-printed condition due to the situations encountered above.

$\mathrm{Ni} 718$ is a nickel-based superalloy that has a combination of high strength at high temperatures, corrosion resistance, and oxidation resistance, in combination with adequate creep and fatigue resistance for general industrial use. ${ }^{3}$ Raza et al. ${ }^{4}$ conducted GTAW of AM Ni 718 in various heat-treated conditions, and found that Ni718 was susceptible to heat-affected zone (HAZ) cracking in all material conditions. That work provided inspiration for continued study exploring the weldability of AM Ni 718.

Previous work has shown that Ni 718 has outstanding weldability, including resistance to postweld cracking. Ni 718 has a relatively slow hardening response, and as a result it can be welded without spontaneous hardening during heating and cooling. ${ }^{5}$ Venukumar et al. conducted an experiment that investigated the effect of welding parameters of Ni 718 alloy using GTAW. They concluded that, when welding 2-mm-thick plates of $\mathrm{Ni} \mathrm{718,} \mathrm{the}$

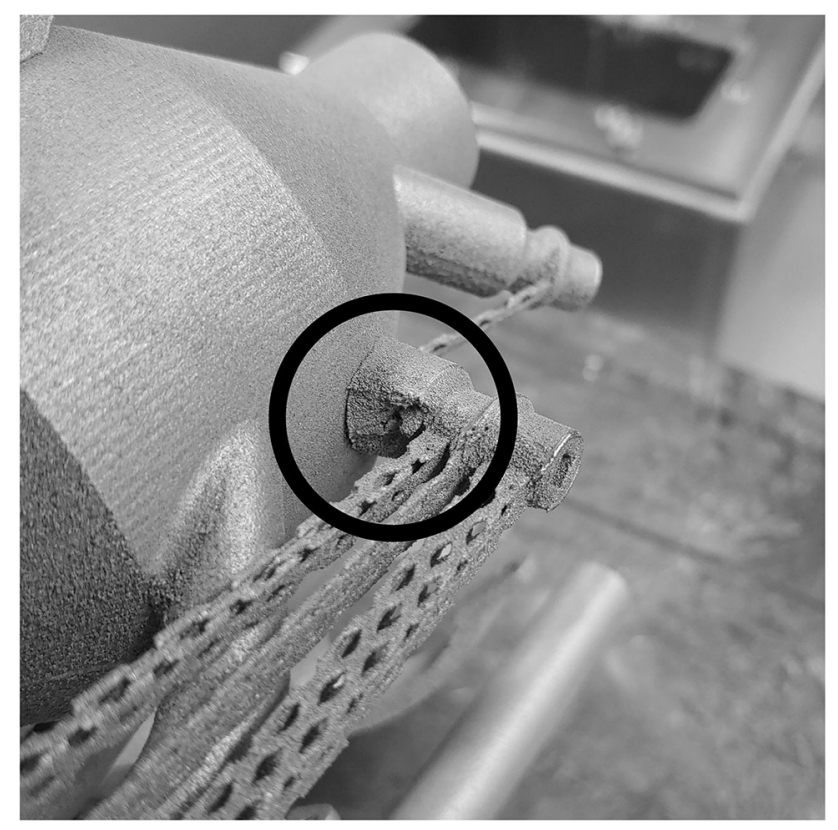

Fig. 1. Defect in printed component due to support failure.

current should be controlled between 60 and 70 amps. Looking with transmission electron microscopy (TEM), it was discovered that both $\gamma^{\prime}$ and $\gamma$ " precipitates can be seen. ${ }^{6}$

Ti-6Al-4V (Ti64) is a common AM titanium alloy due to its favorable combination of physical and mechanical properties. Microstructural changes, such as annealing, recrystallization, and phase transformation into the high-temperature $\beta$ phase during welding, alter the grain size, phase ratios, and microstructural morphologies in the weld region. ${ }^{7}$ Previous work on AM Ti64 has primarily involved wire and arc AM of Ti64. Wang et al. investigated the microstructure and mechanical properties of wire and arc AM Ti64, and found that the microstructure consisted of fine Widmanstätten $\alpha$ in the upper deposited layers and a banded coarsened Widmanstätten lamella $\alpha$ in the lower layers, due to the repeated rapid heating and cooling thermal cycling that occurs during the AM process. ${ }^{8}$ Previous work by $\mathrm{He}$ et al. explored the weld repair of a laser AM similar alloy, Ti-55511, and found that dissolved oxygen in the weld zone leads to distinct microstructures from base metal after annealing, and that the repaired specimens have lower plasticity and slightly higher strength than base metal. ${ }^{9}$ This was inspirational to our work in exploring the weldability of AM Ti64.

AlSi10Mg is the most widely used AM aluminum alloy due to its ease of printability together with characteristic $\mathrm{Al}$ alloy physical properties, such as low weight, good mechanical strength, low cost, and high thermal and electrical conductivity. ${ }^{10}$ One of the main challenges with this material is the low rate of energy absorption promoting defects, such as high porosity. ${ }^{11}$ 
Previous work has produced conflicting results when friction stir welding (FSW) AlSi10Mg. Du et al. ${ }^{12}$ found that a significant decrease in microhardness in the stir zone was observed, Scherillo et al. ${ }^{13}$ determined that welds harder than the parent material can be obtained.

\section{EXPERIMENTAL METHODS}

\section{Print Parameters and Printer Details}

A Concept Laser M2 L-PBF machine equipped with dual 400-W continuous wave Nd:YAG lasers (1064 $\mathrm{nm}$ wavelength) was used to manufacture the nickel and aluminum specimens for this study. The Concept Laser M2 has a gas flow parallel to the recoating direction and is controlled as a function of the percentage of the total gas flow available and the chamber oxygen content. The $\mathrm{Ni} 718$ and AlSi10Mg samples were manufactured in a nitrogen environment utilizing a laser power of $350 \mathrm{~W}$, a slice thickness of $50 \mu \mathrm{m}$, a spot size of $175 \mu \mathrm{m}$, trace spacing of $0.17 \mathrm{~mm}$ and laser speed of $1000 \mathrm{~mm} \mathrm{~s}^{-1}$. The Ti6Al4V specimens were printed in an Arcam Q10Plus EBM machine utilizing standard proprietary Arcam melt themes.

\section{Optical Microscopy and Mechanical Testing}

GTAW was performed with a Lincoln Electric 275 Precision Tig Welder and argon gas at 15 PSI. Each specimen was prepared for optical microscopy using standard metallographic practices. A VibroMet 2 was used to provide a final polish of $0.05 \mu \mathrm{m}$ for each sample. L-PBF GTAW Ni 718 was electrolytically etched using a solution of $10 \% \mathrm{HCl}$ and $90 \%$ distilled water at 5V, EB-PBF GTAW Ti64 was chemically etched using Keller's regent, and the LPBF FSW AlSi10Mg sample was chemically etched using $1 \mathrm{~mL} \mathrm{HF}$ and $200 \mathrm{~mL}$ of distilled water. The L-PBF GTAW AlSi10Mg sample was not etched as a separate process but was polished with $0.05-\mu \mathrm{m}$ colloidal silica suspended in a basic solution, which provided an etch to the metal in the weld region. Each sample was imaged using a standard optical microscope, then Adobe image processing software was used to prepare images for analysis. Hardness testing was performed at room temperature using a Mitutoyo AR-10 hardness tester and the Rockwell Hardness B scale. Figure 2 shows the indentation strategy for the welded samples. Test specimens were cut from the L-PBF GTAW and FSW AlSi10Mg plates to ASTM E8/8 M subsize flat standards using a waterjet with a thickness of 0.25 in $(6.35 \mathrm{~mm})$. Tensile tests were performed on each of the samples at room temperature using an Instron 5985 testing system.

\section{RESULTS AND DISCUSSION}

All the samples were welded in the as-printed condition, and post-mechanical testing and characterization was completed without any post-weld heat treatment. These conditions were selected as this study was meant to be a proof of concept whether the PBF printed parts could be successfully repaired or welded in the as-printed condition, as, in a production environment, post-heat treatment could subsequently be completed to equilibrate the microstructure and relieve stresses without additional heat treatments. Further commentary is included later as well as in the conclusions.

The L-PBF Ni 718 plate was welded with DC values of 75 amps, 100 amps, 125 amps, 150 amps, 175 amps, and 200 amps. Weld pool initiation was not observed at 100 amps or below. Based on our observations, a weld current of 150 amps was selected to produce the most stable weld pool. EBPBF Ti64 was welded with DC values of 75 amps, 100 amps, 125 amps, $150 \mathrm{amps}$, and $175 \mathrm{amps}$. Weld pool initiation was not observed at $125 \mathrm{amps}$ or below. The weld current selected for AM Ti64 was approximately $175 \mathrm{amps}$ to produce the most stable weld pool. L-PBF AlSi10Mg was welded with $\mathrm{AC}$ values of $75 \mathrm{amps}, 100 \mathrm{amps}, 125 \mathrm{amps}$, 110 amps, 95 amps, and 105 amps. Weld pool initiation was not observed at 75 amps or below. It was concluded that the proper current to weld AM AlSi10Mg plate was 25 amps to produce the most stable weld pool.

\section{Transverse Metallographic Views}

\section{Ni 718}

Figure 3 shows the weld and base metal interface of AM samples obtained via optical microscopy. Figure $3 \mathrm{a} 2, \mathrm{~b} 2, \mathrm{c} 2$ and $\mathrm{d} 2$ are the magnified images of the rectangles in $(\mathrm{a}-\mathrm{d})$, respectively. Figure 3a1 show the dendritic growth within the HAZ. The weld zone (carried out at 150 amps current) shows a

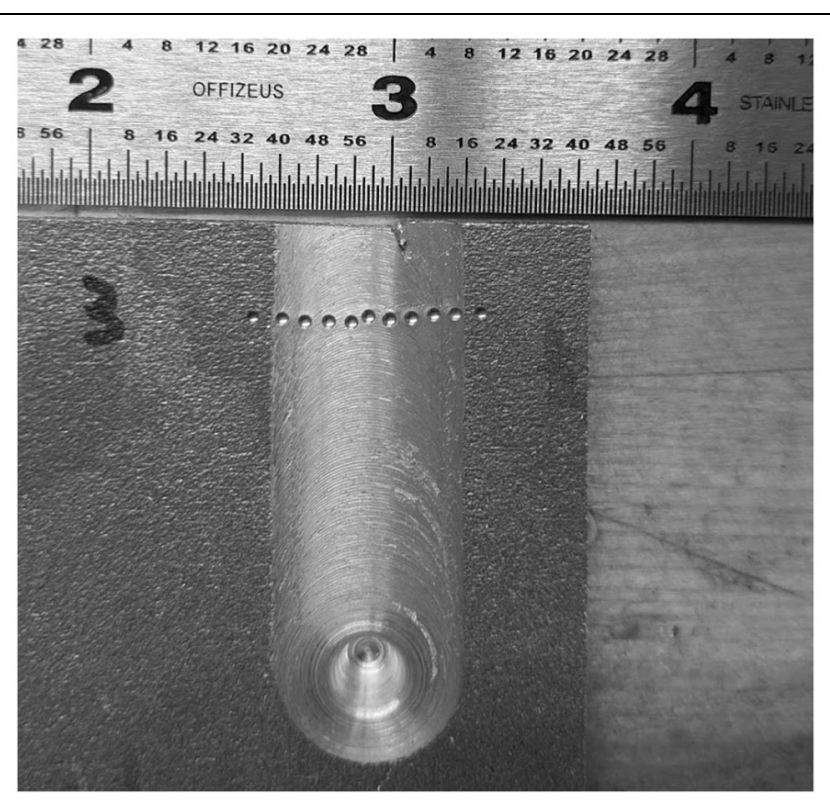

Fig. 2. Welded sample hardness testing indentation methodology. 

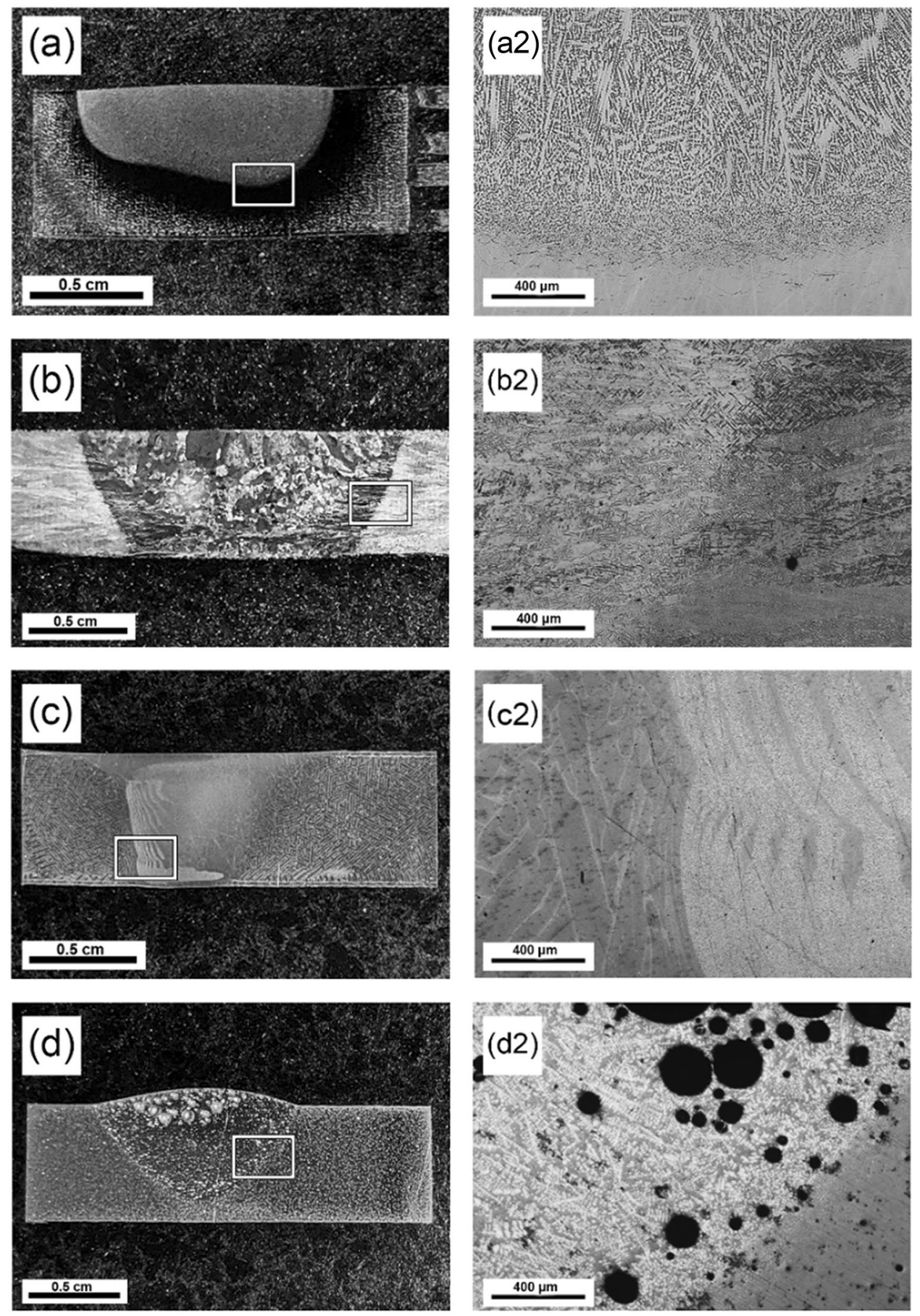

Fig. 3. The weld and base metal interface of additively manufactured samples: (a1) Ni718 GTAW; (b1) Ti6Al4V GTAW; (c1) AISi10Mg FSW; (d1) AISi10Mg GTAW; (a2- d2) the magnified images of the rectangles in (a-d), respectively.

fine dendritic structure at $\times 400$ magnification. Of particular note for this study is the fact that there are no gross porosity defects, showing proof of concept for welding or potentially repairing printed $\mathrm{Ni} 718$ in the as-printed condition.

\section{$T i-6 A l-4 \mathrm{~V}$}

Optical microscopy for the GTAW EB-PBF Ti64 was performed. Figure $3 \mathrm{~b} 2$ shows the definition between the weld zone and the base material. Grain coarsening was observed in the HAZ. Enlarged $\beta$ grains are observed as a result of the welding heating cycle.

\section{AlSi10Mg}

Figure 4 shows optical microscopy images of the as-printed L-PBF AlSi10Mg and shows high porosity in the AlSi10Mg, which is common for 3D- 

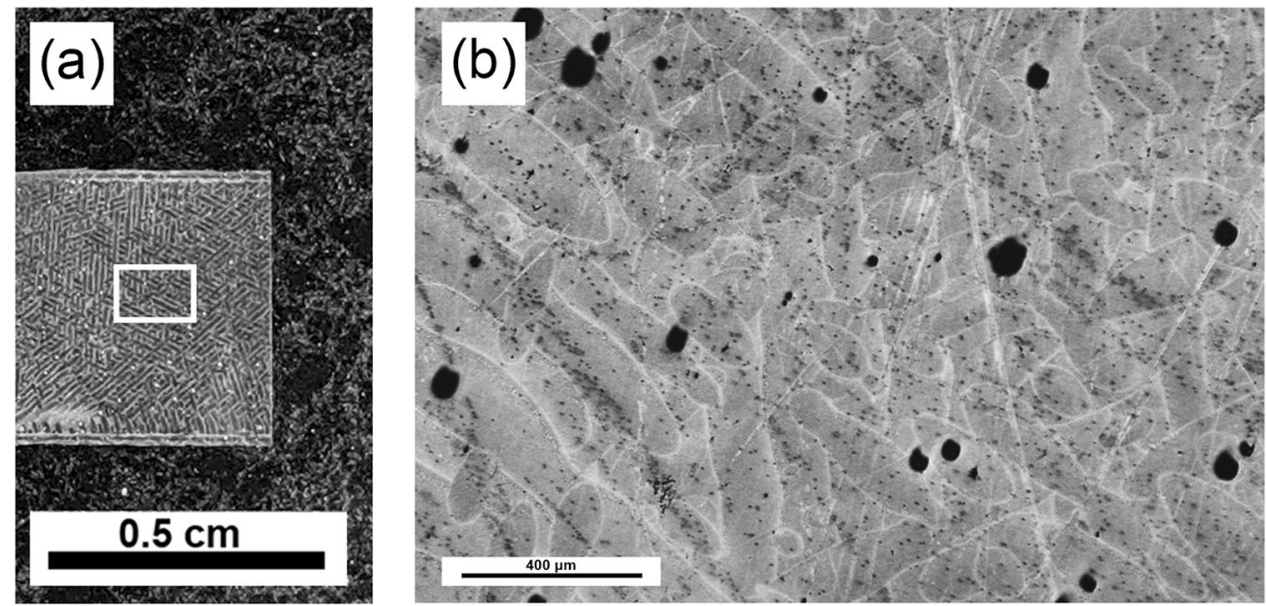

Fig. 4. As-printed AlSi10Mg microstructure; (b) the magnified image of the rectangle in (a).

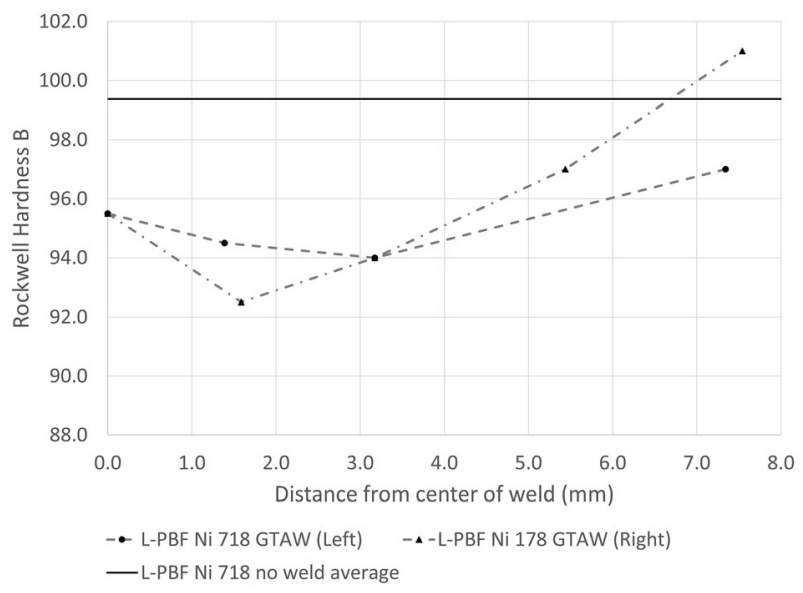

Fig. 5. Rockwell hardness of L-PBF Ni718 after GTAW.

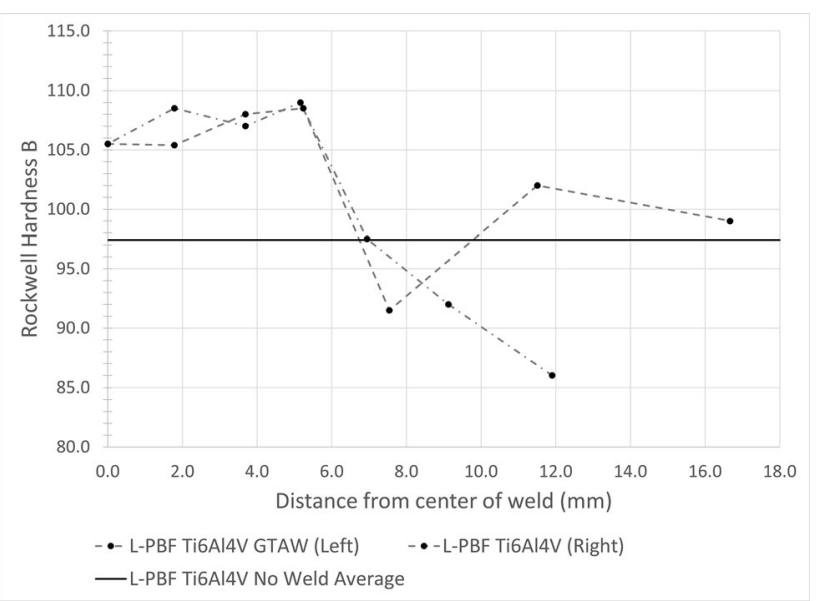

Fig. 6. Rockwell hardness of L-PBF Ti64 after GTAW.

printed AlSi10Mg. ${ }^{9}$ At $\times 400$, the weld pool cross section is observed where, during the AM process, the metal cools and overlaps at varying orientations. The size and spherical shape of the voids are evidence that the voids are caused by gas porosity.

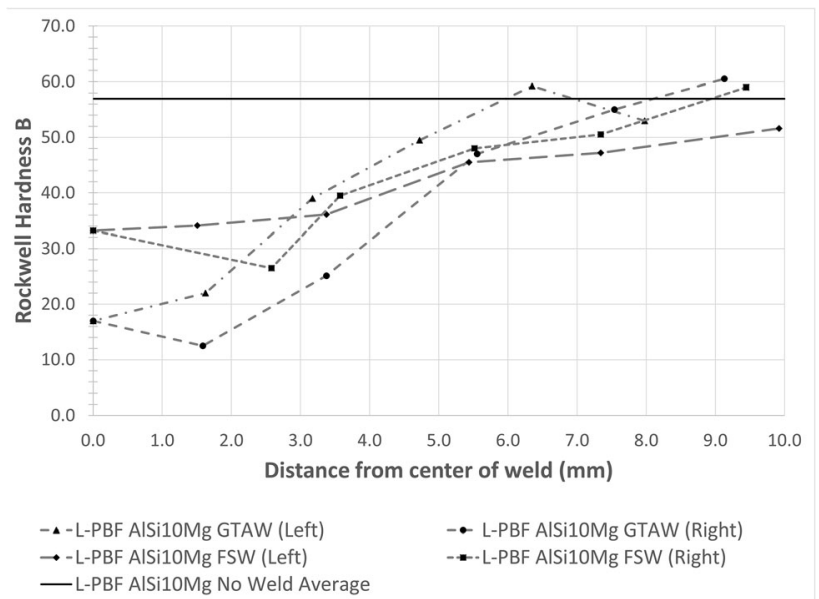

Fig. 7. Rockwell hardness of L-PBF Al after GTAW and FSW.

Optical microscopy of FSW AlSi10Mg was conducted and the results are shown in Fig. 3c2. The banding caused by the rotation of the tool head as it passes through the material can be clearly seen. A clear microstructural difference can be observed between the welded material and the base metal. There is an elimination of voids in the fusion zone as well as a finer grain structure.

Figure 3d shows optical microscopy images of GTAW L-PBF AlSi10Mg. Increased porosity volume can be seen both at the top of the HAZ in (a) and the fusion zone in (b). This was previously observed by Zhanga et al. ${ }^{14}$ who also noted that the pores were filled in after a second welding pass. ${ }^{14}$ The smaller equiaxed solidification zone can be clearly seen in Fig. 3d2 near the weld boundary, which indicates heat dissipation outward towards the base metal. The columnar dendrites seen in the weld metal is typical of the AlSi10Mg weld structure. ${ }^{14}$ 
Table I. Tensile testing results of L-PBF AlSi ${ }_{10} \mathrm{Mg}$

\begin{tabular}{|c|c|c|c|c|}
\hline L-PBF AlSi ${ }_{10}$ Mg sample & Concept laser technical data ${ }^{17}$ & As-printed & GTAW & FSW \\
\hline Yield strength $(\mathrm{MPa})$ & 155 & 133.1 & 94.9 & 73.4 \\
\hline Tensile strength (MPa) & 300 & 296.6 & 194.2 & 200.4 \\
\hline Elongation $(\%)$ & 7.0 & 4.8 & 3.1 & 4.8 \\
\hline Young's modulus (GPa) & 75 & 65.7 & 65.3 & 55.3 \\
\hline
\end{tabular}

\section{Mechanical Properties}

\section{Ni 718}

Figure 5 shows the Rockwell hardness of L-PBF Ni718 after GTAW. The hardness of the metal decreased when moving from the fusion zone to the heat-affected zone, which was most likely due to precipitation of $\gamma$ " at the fusion site hardening the material, which has been observed in cold-rolled sheets of Ni 718 from previous work. ${ }^{13}$ Post-weld heat treatment could be used to equilibrate the microstructure and consequently the hardness and mechanical properties.

\section{$T i-6 A l-4 \mathrm{~V}$}

Figure 6 shows the Rockwell hardness of L-PBF Ti64 after GTAW. The hardness was greater in the fusion area than in the heat-affected zone and base material. Gao et al. ${ }^{15}$ observed the formation of the martensitic $\alpha^{\prime}$ structure that affects the hardness. This agrees with the observations of the HAZ. The lowered strength seen in the previous work's hardness results for GTAW welding of PBF parts was attributed to the filler wire used having a lower strength in contrast to this work, which was autogenous joining with no filler metal. While the Ti64 was able to be welded without significant porosity, the differences in hardness require a post-weld heat treatment to avoid premature failure.

\section{AlSi10Mg}

Figure 7 shows the Rockwell hardness of L-PBF Al after GTAW and FSW. The hardness at the center of the welds was less than that of the as-built LPBF AlSi10Mg material. In a study conducted by $\mathrm{Li}$ et al., it was shown that heat-treating L-PBF $\mathrm{AlSi} 10 \mathrm{Mg}$ caused nanoparticles of $\mathrm{Si}$ in the $\mathrm{Al}$ matrix to precipitate out of the sample, which caused the non-heat-treated samples to perform better in the hardness test. ${ }^{16}$ The heating cycle used during FSW affected the sample in a similar way, and was shown in a previous study on selective laser-melted FSW AlSi10Mg. ${ }^{11}$ The FSW process produced a lower heat input into the sample than GTAW, therefore fewer of the nano-Si particles precipitated out of the $\mathrm{Al}$ matrix. Literature values observed the lowest micro-hardness at $3 \mathrm{~mm}$ from the center. ${ }^{11}$ This is in agreement with the FSW test performed where the lowest hardness was achieved at $2.54 \mathrm{~mm}$. Future work could include TEM observations of the Si nanoparticles to support the hardness measurement.

Tensile testing was conducted on the L-PBF AlSi10Mg sample and the results are included in Table I. The as-built tensile data is in agreement with the manufacturer's published data. ${ }^{17}$ Both of the welded samples had a lower yield strength, tensile strength, and elongation than the as-printed sample. Between the two welds, the tensile strength was similar, but the yield strength of the FSW AlSi10Mg was lower than in the GTAW AlSi10Mg. These measured values can be explained by the additional heating and cooling from the welding process, as well as from the introduction of large amounts of porosity in the GTAW AlSi10Mg. Further testing of additional replicates and including microstructural characterization would add to the observations in this screening study. AlSi10Mg is a more difficult alloy to print with a high density as compared to Ni 718 and Ti64, with that difficulty extending to post-printing welding.

\section{CONCLUSIONS}

This work includes a screening study that characterizes the microstructural and mechanical properties of metal parts produced through L-PBF and EB-PBF and subsequently welded. All the samples were welded in the as-printed condition and characterized without post -eld heat treatment, in order to evaluate the potential for completing repair and rework of printed metal AM parts without adding additional heat-treatment steps to a production workflow. The results show possibilities for GTAW and FSW as feasible rework and repair solutions for AM-printed AlSi10Mg, Ni 718, and Ti64. The Ni718 and Ti64 were straightforward to weld, while the AlSi10Mg welding was possible but showed large amounts of defects, particularly in the GTAW AlSi10Mg microstructure. Additional work, including post-weld heat treatment to characterize the ability to erase the as-welded microstructure and level the hardness values across the welded area,will further advance the state of the art.

\section{CONFLICT OF INTEREST}

On behalf of all authors, the corresponding author states that there is no conflict of interest. 


\section{REFERENCES}

1. E.D. Herderick, JOM 67, 580 (2015).

2. NASA Technical Standards System, MFSC-STD3716 - Standard for Additively Manufactured Spaceflight Hardware by Laser Powder Bed Fusion in Metals, NASA Technical Standards System (2017). https://www.nasa.gov/ sites/default/files/atoms/files/msfcstd3716baseline.pdf.

3. G.A. Knorovsky, M.J. Cieslak, T.J. Headley, A.D. Romig, and W.F. Hammetter, Metall. Trans. A 20, 2149 (1989). h ttps://doi.org/10.1007/BF02650300.

4. T. Raza, K. Hurtig, G. Asala, J. Andersson, L.-E. Svensson, and O.A. Ojo, Metals 9, 881 (2019).

5. R.M. Evans, The Welding and Brazing of Alloy 718, Vol. 204 (Columbus: Defense Metals Information Center, Battelle Memorial Institute, 1964).

6. S. Venukumar, P. Sarkar, J. Sai Sashank, P. Sampath, and K. Saikiran, Mater. Today: Proc. 5, 8480 (2018).

7. J.W. Elmer, T.A. Palmer, S.S. Babu, W. Zhang, and T. DebRoy, J. Appl Phys. 95, 8327 (2004).

8. F. Wang, S. Williams, P. Colegrove, and A.A. Antonysamy, Metall. Mater. Trans. A 44, 968 (2013).

9. B. He, X.-J. Tian, J.L. Cheng, and H.-M. Wang, Mater Design 119, 437 (2017).
10. M. Javidani, J. Arreguin-Zavala, J. Danovitch, Y. Tian, and M. Brochu, J. Therm. Spray Technol. 26, 587 (2017). http s://doi.org/10.1007/s11666-016-0495-4.

11. N.T. Aboulkhair, N.M. Everitt, I. Ashcroft, and C. Tuck, Addit. Manuf. 1-4, 77-86 (2014). https://doi.org/10.1016/j.a ddma.2014.08.001.

12. Z. Du, M.J. Tan, H. Chen, G. Bi, and C.K. Chua, Weld World 62, 675 (2018). https://doi.org/10.1007/s40194-018-0585-7.

13. F. Scherillo, A. Astarita, U. Prisco, V. Contaldi, P. di Petta, A. Langella, and A. Squillace, Metallogr. Microstruct. Anal. 7, 457 (2018). https://doi.org/10.1007/s13632-018-0465-y.

14. C. Zhang, Y. Bao, H. Zhu, X. Nie, W. Zhang, S. Zhang, and X. Zeng, Optics Laser Technol. 120, 105696 (2019).

15. X.-L. Gao, L.-J. Zhang, J. Liu, and J.-X. Zhang, Mater. Sci. Eng., A 559, 14 (2013).

16. W. Li, S. Li, J. Liu, A. Zhang, Y. Zhou, Q. Wei, C. Yan, and Y. Shi, Mater. Sci. Eng.: A 663, 116 (2016).

17. Concept Laser, CL 32Al Aluminum Alloy (GE Additive, 2018), https://www.ge.com/additive/sites/default/files/201812/CL\%2032AL_DS_DE_US_v1.pdf.

Publisher's Note Springer Nature remains neutral with regard to jurisdictional claims in published maps and institutional affiliations. 